\title{
Kapasitas Lentur Balok Beton Tulangan Bambu Ori Takikan Jarak 20 dan 30 mm
}

\author{
Agus Setiya Budi \\ Prodi Teknik Sipil, Universitas Sebelas Maret \\ J1. Ir. Sutami 36 A Surakarta \\ E-mail: asb.asb09@yahoo.co.id \\ Endang Rismunarsi \\ Prodi Teknik Sipil, Universitas Sebelas Maret \\ Jl. Ir. Sutami 36 A Surakarta \\ E-mail: rismunarsi@yahoo.co.id \\ Kharir \\ Prodi Teknik Sipil, Universitas Sebelas Maret \\ J1. Ir. Sutami 36 A Surakarta \\ E-mail: kharir11@yahoo.co.id
}

\begin{abstract}
Bamboo is one of the potential material as a substitute for steel reinforcement. This paper will discuss the flexural capacity of concrete beam with Ori bamboo reinforcement notch $V$ type. The use of the notch is expected to minimize the effects of shrinkage and slip. This study uses laboratory experimental method. Bamboo is used at least 2.5 years old. Bamboo in a notch with a $V$-shape with the distance between the notch is $2 \mathrm{~cm}$ and $3 \mathrm{~cm}$. The sample size used in the form of a concrete beam is $11 \times 15 \times 170 \mathrm{~cm}$. The compressive strength of concrete ( $f c^{\prime}$ ) used was $18.3 \mathrm{MPa}$, yield strength of bamboo (fyb) with nodia is $276.56 \mathrm{MPa}$, and a yield strength of steel (fys) is $486.6 \mathrm{MPa}$. Static loading is done with third point loading system. For comparison also tested steel reinforcement concrete beam with $\emptyset-8 \mathrm{~mm}$. Based on test results, the average value of flexural capacity test on a sample of concrete beams reinforced bamboo Ori $V$ notches on the distance between the notch $20 \mathrm{~mm}$ is $0.412 \mathrm{tm}$, and the average value of flexural capacity on the distance between the notch $30 \mathrm{~mm}$ is $0.387 \mathrm{tm}$ and the average value of flexural capacity of concrete beam test with steel reinforcement $\emptyset-8 \mathrm{~mm}$ is $0.516 \mathrm{tm}$.
\end{abstract}

Keywords: Concrete beams, Bamboo reinforcement, Flexural capacity, Ori bamboo.

\begin{abstract}
Abstrak
Salah satu alternatif pengganti tulangan baja yang potensial untuk konstruksi bangunan sederhana adalah bambu. Makalah ini akan membahas kapasitas lentur balok beton tulangan bambu Ori dengan takikan tipe V. Penggunaan takikan diharapkan dapat meminimalkan efek susut dan slip. Penelitian ini menggunakan metode eksperimental laboratorik. Bambu yang digunakan adalah bilah bambu Ori yang telah berumur minimal 2,5 tahun. Bilah bambu diberi takikan V dengan jarak antar takikan $20 \mathrm{~mm}$ dan $30 \mathrm{~mm}$. Sampel balok beton yang digunakan berukuran $11 \times 15 x 170 \mathrm{~cm}$. Mutu beton (fc')18,3 MPa, kuat leleh bambu (fy $\left.y_{b}\right)$ dengan nodia adalah 276,56 MPa dan kuat leleh baja $\left(f y_{s}\right)$ 486,6 MPa. Pembebanan statik dilakukan dengan cara Third Point Loading. Sebagai pembanding diuji pula balok beton dengan tulangan baja $\varnothing 8 \mathrm{~mm}$. Berdasarkan hasil pengujian, didapat kapasitas lentur rerata hasil uji pada benda uji balok beton tulangan bambu Ori takikan V dengan jarak antar takikan $20 \mathrm{~mm}$ adalah 0,412 tm, dan kapasitas lentur rerata dengan jarak antar takikan $30 \mathrm{~mm}$ adalah 0,387 tm serta kapasitas lentur rerata balok beton dengan tulangan baja $\emptyset 8 \mathrm{~mm}$ sebesar 0,516 tm.
\end{abstract}

Kata-kata Kunci: Balok beton, Tulangan bambu, Kapasitas lentur, Bambu Ori. 


\section{Pendahuluan}

Bambu memiliki keunggulan berupa kuat tarik serat sisi kulit yang cukup tinggi yang dapat dipersaingkan dengan baja lunak. Hal ini menjadikan bambu sebagai salah satu alternatif pengganti tulangan baja yang potensial untuk bangunan khususnya untuk konstruksi sederhana. Di Indonesia, ketersediaan bahan baku material bambu ini di alam masih sangat melimpah, terutama di daerah pedesaan. Oleh sebab itu perlu dikembangkan penggunaan bambu sebagai alternatif pengganti baja pada beton utamanya pada konstruksi bangunan sederhana.

Penelitian bambu sebagai pengganti tulangan baja ini telah banyak dilakukan. Kendala yang sering dijumpai pada penggunaan bambu ini adalah efek susut material bambu dan perilaku slip bambu pada beton. Tujuan yang hendak disampaikan pada makalah ini adalah penggunaan tulangan bambu yang telah dimodifikasi dengan menggunakan takikan yang diharapkan dapat menambah kapasitas lentur balok beton. Makalah ini membahas kapasitas lentur balok beton tulangan bambu Ori dengan takikan tipe $\mathrm{V}$ dengan jarak takikan $20 \mathrm{~mm}$ dan $30 \mathrm{~mm}$.

\section{Karakteristik Material}

\section{Bambu}

Jenis bambu yang digunakan dalam penelitian ini adalah jenis bambu Ori. Diperoleh dari daerah Dukuh Jlegong, Desa Banyu Urip, Kecamatan Klego, Kabupaten Boyolali.

1. Sifat Fisika

Pengujian sifat fisika bambu Ori dilakukan di Laboratorium Bahan Fakultas Teknik, Universitas Sebelas Maret Surakarta. Berdasarkan hasil uji material, diperoleh kadar air sebesar $11,21 \%$ dan kerapatan sebesar $1,068 \mathrm{gram} / \mathrm{cm}^{3}$.

2. Sifat Mekanika

Nilai kuat geser sejajar serat sebesar 7,013 $\mathrm{N} / \mathrm{mm}^{2}$ dan kuat tekan sejajar serat sebesar $53,11 \mathrm{~N} / \mathrm{mm}^{2}$. Nilai kuat tarik sejajar serat internodia sebesar $470,62 \mathrm{~N} / \mathrm{mm}^{2}$, kuat tarik sejajar serat nodia sebesar 276,56 N/mm², nilai kuat tarik bambu yang digunakan adalah nilai terkecil.

\section{Baja}

Tulangan baja $\varnothing \quad 8 \mathrm{~mm}$ digunakan sebagai pembanding dari tulangan bambu. Uji kuat tarik baja dilakukan untuk mendapatkan nilai kuat tarik dari baja. Hasil pengujian kuat tarik tulangan baja didapatkan hasil kuat tarik leleh rata-rata sebesar 486,6 $\mathrm{MPa}$ dan kuat tarik maksimum sebesar 638,2 MPa.

\section{Beton}

Nilai kuat desak beton diperoleh dari hasil pengujian tiga buah benda uji berbentuk silinder dengan diameter $150 \mathrm{~mm}$ dan tinggi $300 \mathrm{~mm}$, Pengujian kuat desak beton dilakukan saat beton berumur 28 hari, dimana dari hasil pengujian didapat rerata kuat desak beton sebesar 18,29 $\mathrm{N} / \mathrm{mm}^{2}$. Nilai slump dari campuran adukan beton pada penelitian ini adalah $12 \mathrm{~cm}$.

\section{Penampang tulangan bambu takikan}

Pendekatan model tulangan bambu dilakukan dengan membuat takikan pada bagian sisi. Hal ini diharapkan akan meningkatkan kuat lekat antara bambu dan beton seperti penggunaan tulangan baja ulir (steel deformed bar). Tulangan bambu bertakikan dapat mengurangi pengaruh penyusutan atau pengembangan karena kandungan air, dengan adanya bagian saling mengunci antara permukaan tulangan dan beton. (Azadeh, 2013).

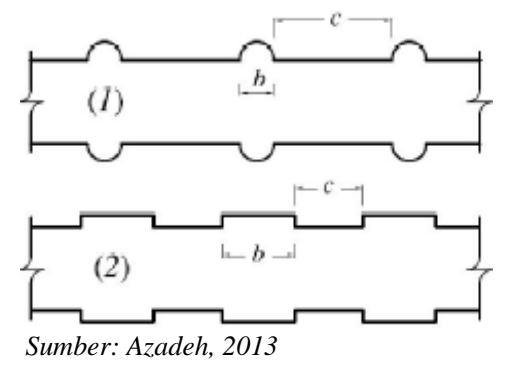

\section{Gambar 1. Tipikal bentuk tulangan baja deformasi dan bambu takikan.}

Berikut ini dalam Gambar 2 disajikan bentuk tipe tulangan bambu takikan jarak $30 \mathrm{~mm}$.

\section{Setting Pengujian}

Pengujian kuat lentur dilakukan pada benda uji balok dengan dimensi lebar $110 \mathrm{~mm}$, tinggi 150 $\mathrm{mm}$, dan panjang $1700 \mathrm{~mm}$, dengan jumlah benda uji balok sebanyak 12 buah yang terdiri dari 3 buah balok bertulangan baja, 6 buah balok bertulangan bambu takikan tipe $\mathrm{V}$. Untuk skema pengujian kuat lentur dapat dilihat pada Gambar 3.

Data hasil pengujian kuat lentur yang didapat antara lain beban dan lendutan yang dibaca melalui Transducer pada Hidraulic Jack dan Dial Gauge dengan interval pembebanan $50 \mathrm{~kg}$. 

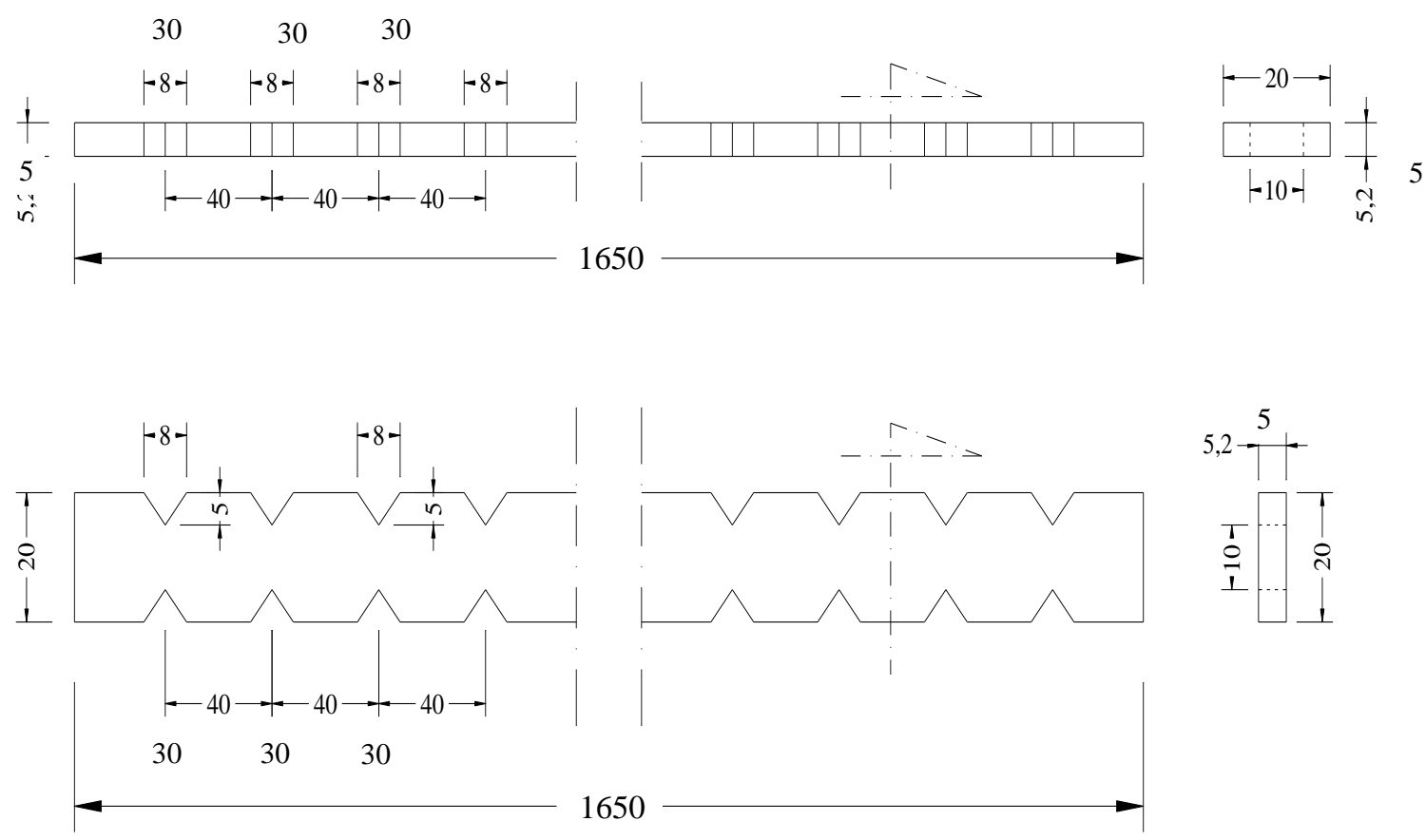

Gambar 2. Bambu takikan jarak 30 mm

Beban

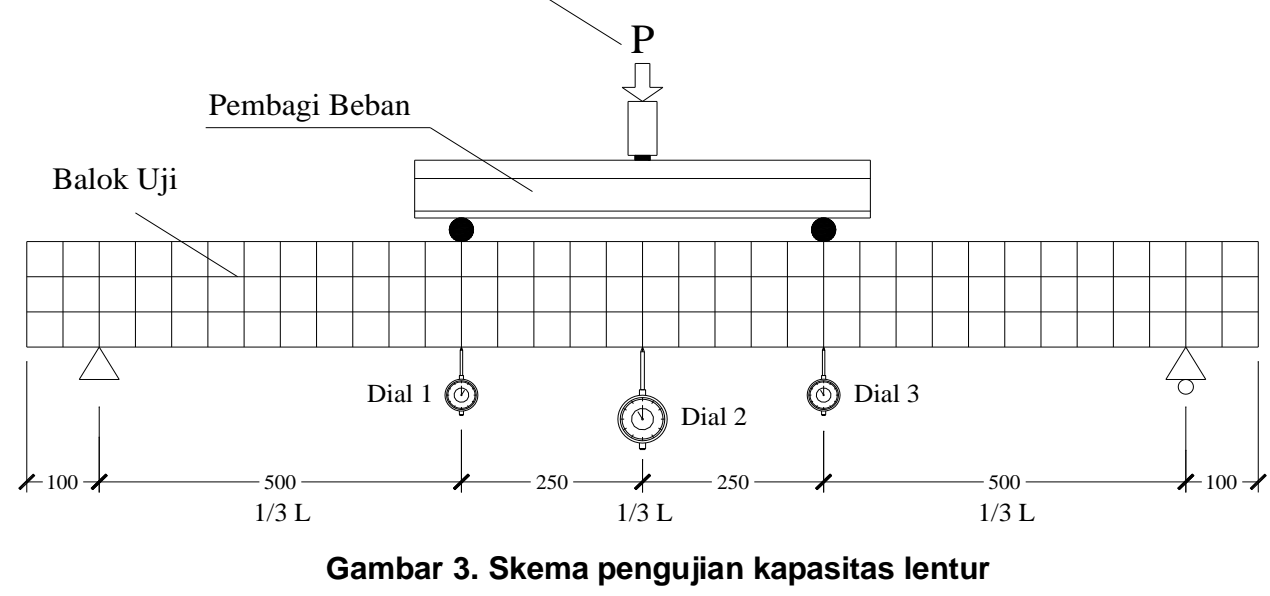

\section{Hasil Pengujian}

Berikut ini dalam Gambar 4 disajikan grafik hubungan beban dan lendutan dari hasil pengujian.

\section{Analisis data}

Momen maksimum

Perhitungan Momen Maksimum hasil pengujian ini menggunakan konsep statika dimana simple beam dibebani dengan beban merata dan beban terpusat sebesar $\mathrm{P} / 2$ pada sepertiga bentangnya.
Perhitungan momen nominal analisis

Perhitungan momen nominal (Mn) hasil analisis dilakukan untuk pembanding dari hasil pengujian benda uji. Analisis dilakukan pada balok bertulangan baja dan bambu. Distribusi tegangan dan regangan pada penampang beton dapat dilihat pada Gambar 5 .

Hasil perhitungan Mn dan Pmax hasil analisis balok bertulang dapat dilihat pada Tabel 2 . 


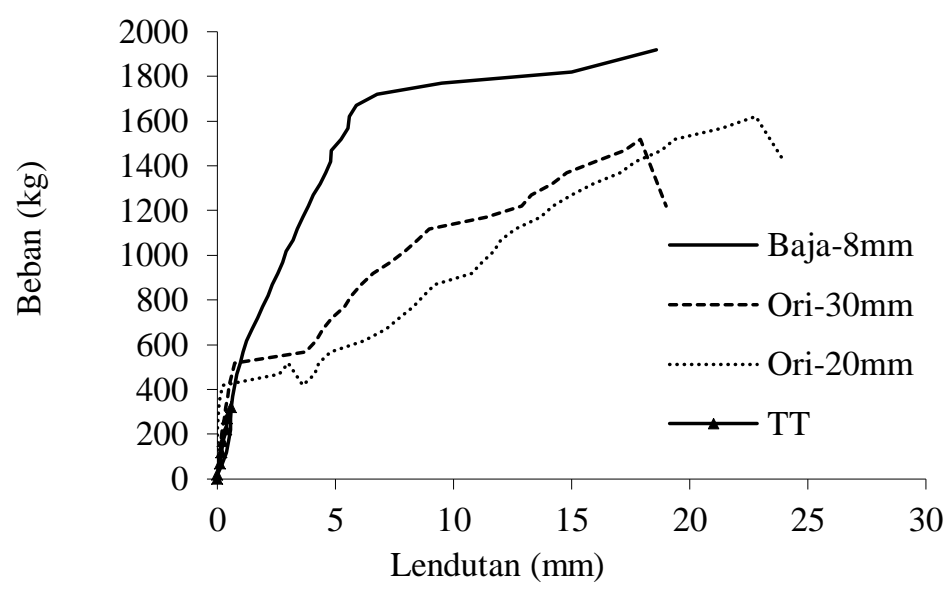

Gambar 4. Grafik hubungan beban dan lendutan

Tabel 1. Hasil perhitungan momen maksimum pengujian

\begin{tabular}{|c|c|c|c|c|c|}
\hline \multirow{3}{*}{ Nama benda uji } & \multirow{2}{*}{\multicolumn{2}{|c|}{ P maks }} & \multirow{3}{*}{$\begin{array}{c}\text { P maks rerata } \\
\text { (ton) }\end{array}$} & \multicolumn{2}{|c|}{ Momen maks pengujian } \\
\hline & & & & \multirow{2}{*}{$\frac{\text { Hasil }}{\text { (ton.m) }}$} & \multirow{2}{*}{$\begin{array}{l}\text { Rerata } \\
\text { (ton.m) }\end{array}$} \\
\hline & (kg) & $(\mathbf{N})$ & & & \\
\hline O1-20 mm & 1768,8 & 17688 & & 0,453 & \\
\hline $\mathrm{O} 2-20 \mathrm{~mm}$ & 1668,8 & 16688 & 1,602 & 0,428 & 0,412 \\
\hline $\mathrm{O} 3-20 \mathrm{~mm}$ & 1368,8 & 13688 & & 0,353 & \\
\hline O1-30 mm & 1318,8 & 13188 & & 0,341 & \\
\hline $\mathrm{O} 2-30 \mathrm{~mm}$ & 1368,8 & 13688 & 1,502 & 0,353 & 0,387 \\
\hline $\mathrm{O} 3-30 \mathrm{~mm}$ & 1818,8 & 18188 & & 0,466 & \\
\hline TB- 1 & 1918,8 & 19188 & & 0,491 & \\
\hline TB-2* & 368,8 & 3688 & 2,019 & 0,103 & 0,516 \\
\hline TB-3 & 2118,8 & 21188 & & 0,541 & \\
\hline
\end{tabular}

Keterangan:

$\mathrm{O}-20 \mathrm{~mm}=$ Balok tulangan bambu Ori takikan jarak $20 \mathrm{~mm}$

$\mathrm{O}-30 \mathrm{~mm}=$ Balok tulangan bambu Ori takikan jarak $30 \mathrm{~mm}$

TB $=$ Balok tulangan baja $\varnothing 8 \mathrm{~mm}$

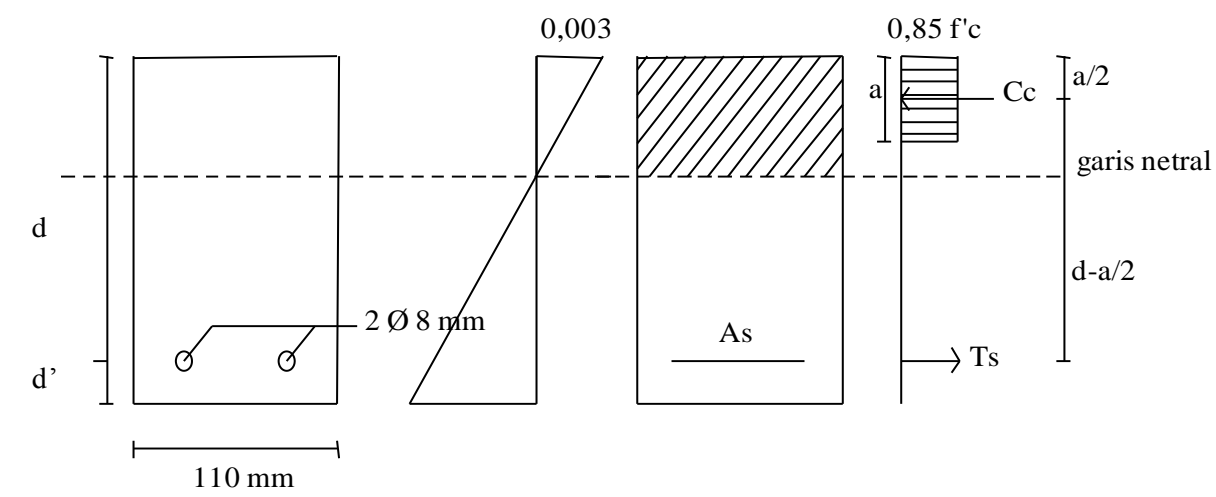

Gambar 5. Distribusi tegangan dan regangan pada penampang beton

Tabel 2. Pmax dan Mn hasil analisis

\begin{tabular}{clcccc}
\hline No & Jenis tulangan & $\begin{array}{c}\mathbf{f y} \\
\mathbf{N} / \mathbf{m m}^{2}\end{array}$ & $\begin{array}{c}\mathbf{A s} \\
\mathbf{m m}^{\mathbf{2}}\end{array}$ & $\begin{array}{c}\mathbf{M n} \\
\text { (ton.m) }\end{array}$ & $\begin{array}{c}\text { Pmax } \\
\text { (ton) }\end{array}$ \\
\hline 1 & Baja & 486,599 & 96,589 & 0,504 & 1,973 \\
2 & Bambu Nodia & 276,560 & 104,000 & 0,328 & 1,267 \\
3 & Bambu Internodia & 470,616 & 104,000 & 0,529 & 2,072 \\
\hline
\end{tabular}




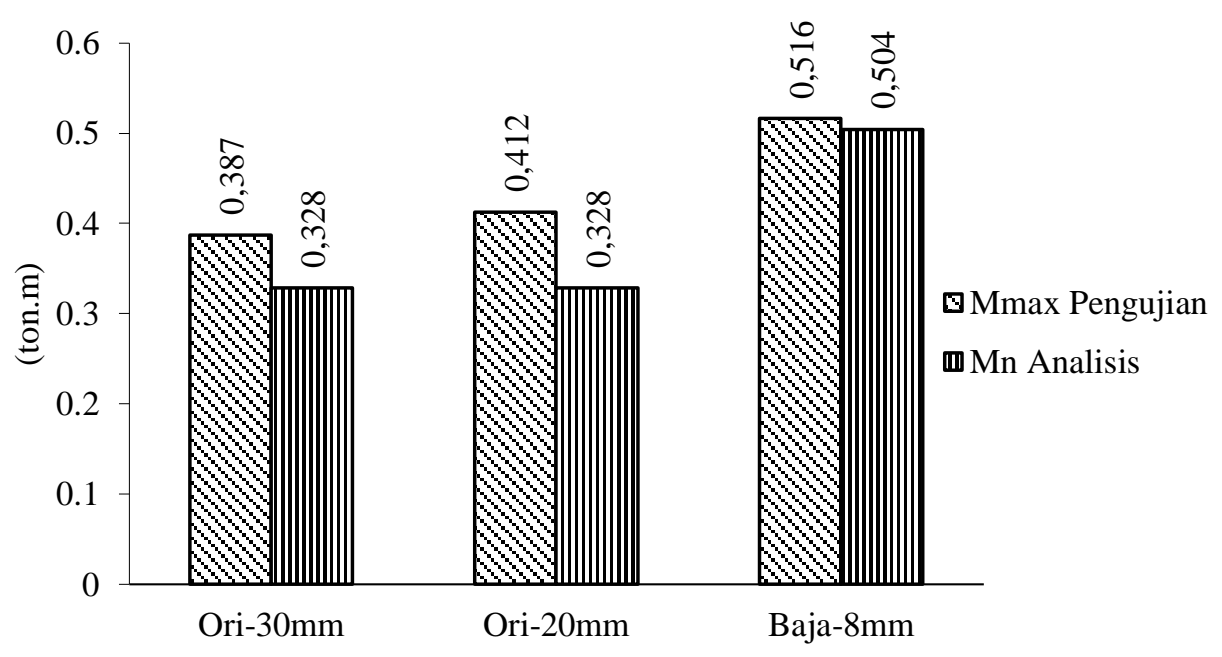

Gambar 6. Perbandingan Mmax pengujian dan Mn analisis

Hasil Mmax pengujian dan perhitungan Mn analisis pada balok bertulangan baja dan bambu dapat dilihat pada Tabel 3.

Tabel 3. Mmax pengujian dan Mn analisis

\begin{tabular}{ccc}
\hline $\begin{array}{c}\text { Jenis } \\
\text { tulangan }\end{array}$ & $\begin{array}{c}\text { Mmax pengujian } \\
\text { (ton.m) }\end{array}$ & $\begin{array}{c}\text { Mn analisis } \\
\text { (ton.m) }\end{array}$ \\
\hline O-20 mm & 0,412 & 0,328 \\
O-30 mm & 0,387 & 0,328 \\
Tul. Baja & 0,516 & 0,504 \\
\hline
\end{tabular}

Berdasar Tabel 3, dalam Gambar 6 disajikan gambar grafik perbandingan Mmax pengujian dan Momen nominal (Mn) analisis balok bertulangan bambu dan baja.

\section{Kesimpulan}

Berdasarkan hasil pembahasan diatas, dapat disimpulkan bahwa:

1. Kapasitas lentur rerata hasil uji pada benda uji balok beton tulangan bambu Ori takikan V dengan jarak antar takikan $20 \mathrm{~mm}$ adalah 0,412 tm, dan kapasitas lentur rerata dengan jarak antar takikan $30 \mathrm{~mm}$ adalah 0,387 tm serta kapasitas lentur rerata balok beton dengan tulangan baja $\varnothing 8 \mathrm{~mm}$ sebesar 0,516 tm.

2. Mmax hasil pengujian balok tulangan bambu Ori jarak $20 \mathrm{~mm}$ sekitar $79,8 \%$ terhadap balok bertulangan baja $\varnothing 8 \mathrm{~mm}$.

3. Mmax hasil pengujian balok tulangan bambu Ori jarak $30 \mathrm{~mm}$ sekitar 74,9\% terhadap balok bertulangan baja $\varnothing 8 \mathrm{~mm}$.

\section{Ucapan Terima Kasih}

Penulis ucapkan terimakasih kepada LPPM UNS atas bantuan dana penelitian, Laboratorium Bahan dan Struktur Prodi Teknik Sipil UNS dan Laboratorium Material Jurusan Teknik Mesin UNS atas fasilitas dan terlaksananya penelitian ini.

\section{Daftar Pustaka}

Azadeh, A., 2013. New Approaches to Bond Between Bamboo and Concrete, $14^{\text {th }}$ International Conference on Non-Conventional Materials and Technologies, 24th-27th March 2013, Federal University of Paraíba, Brasil.

Ghavami, K., 2001. Structural Concrete Elements Reinforced With Bamboo, Asian Journal Of Civil Engineering (Building And Housing) Vol. 2, No. 2 (2001) Pages 97-110.

Istimawan, D., 1994. Struktur Beton Bertulang. PT. Gramedia Pustaka Utama, Jakarta.

Janssen, J.J.A., 1987. The Mechanical Properties of Bamboo: 250-256. In Rao, A.N., Dhanarajan, and Sastry, C.B., Recent Research on Bamboos, The Chinese Academy of Forest, People's Republic of China, and IDRC, Canada.

Morisco, 1999. Rekayasa Bambu, Nafiri Offset, Yogyakarta.

Setiyabudi, A., 2010. Tinjauan Jenis Perekat pada Balok Laminasi Bambu terhadap Keruntuhan Lentur, Prosiding Seminar Nasional, Pengelolaan Infrastruktur Dalam Menyikapi Bencana Alam, ISBN: 979-489-540-6, Surakarta, 1 Mei 2010. 